\title{
Phylogenetic diversity and activity screening of cultivable Actinobacteria isolated from marine sponges and associated environments from the western coast of India
}

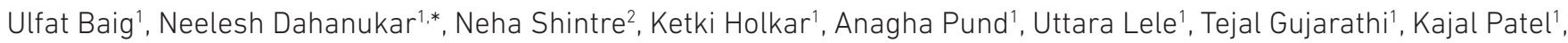 \\ Avantika Jakati¹, Ruby Singh¹, Harshada Vidwans¹, Vaijayanti Tamhane ${ }^{3}$, Neelima Deshpande ${ }^{2}$ and Milind Watve ${ }^{4}$
}

\begin{abstract}
The phylogenetic diversity of cultivable actinobacteria isolated from sponges (Haliclona spp.) and associated intertidal zone environments along the northern parts of the western coast of India were studied using 16 S rRNA gene sequences. A subset of randomly selected actinobacterial cultures were screened for three activities, namely predatory behaviour, antibacterial activity and enzyme inhibition. We recovered 237 isolates from the phylum Actinobacteria belonging to 19 families and 28 genera, which could be attributed to 95 putative species using maximum-likelihood partition and 100 putative species using Bayesian partition in Poisson tree processes. Although the trends in the discovery of actinobacterial genera isolated from sponges were consistent with previous studies from different study areas, we provide the first report of nine actinobacterial species from sponges. We observed widespread non-obligate epibiotic predatory behaviour in eight actinobacterial genera and we provide the first report of predatory activity in Brevibacterium, Glutamicibacter, Micromonospora, Nocardiopsis, Rhodococcus and Rothia. Sponge-associated actinobacteria showed significantly more predatory behaviour than environmental isolates. While antibacterial activity by actinobacterial isolates mainly affected Gram-positive target bacteria with little or no effect on Gram-negative bacteria, predation targeted both Gram-positive and Gram-negative prey with equal propensity. Actinobacterial isolates from both sponges and associated environments produced inhibitors of serine proteases and angiotensin-converting enzyme. Predatory behaviour was strongly associated with inhibition of trypsin and chymotrypsin. Our study suggests that the sponges and associated environments of the western coast of India are rich in actinobacterial diversity, with widespread predatory activity, antibacterial activity and production of enzyme inhibitors. Understanding the diversity and associations among various actinobacterial activities - with each other and the source of isolation - can provide new insights into marine microbial ecology and provide opportunities to isolate novel therapeutic agents.
\end{abstract}

\section{INTRODUCTION}

The marine ecosystem is not only diverse with respect to the micro-organisms found in it but also the natural products being synthesized by these micro-organisms [1-3]. Actinobacteria are among the taxa rich in secondary metabolites [4] and are widely distributed in diverse habitats, including soil, marine and freshwater and sediment $[1,2,5-8]$. They are also common in extreme environments [9-14] and are found as endobiotic symbionts of higher organisms [2, 15-19]. They belong to the phylum Actinobacteria and represent one of the major phyla within the bacterial domain [20]. Widely distributed in aquatic and terrestrial habitats, actinobacteria are Gram-positive or Gram-variable aerobes, facultative anaerobes or anaerobes with rigid cell wall containing muramic acid, and are phenotypically diverse, ranging from

Received 27 July 2020; Accepted 10 June 2021; Published 21 September 2021

Author affiliations: ${ }^{~ I n d i a n ~ I n s t i t u t e ~ o f ~ S c i e n c e ~ E d u c a t i o n ~ a n d ~ R e s e a r c h, ~ P u n e ~(I I S E R-P), ~ D r ~ H o m i ~ B h a b h a ~ R o a d, ~ P a s h a n, ~ P u n e ~ 411008, ~ M a h a r a s h t r a, ~}$ India; ${ }^{2}$ Department of Microbiology, M.E.S. Abasaheb Garware College, Pune 411004, Maharashtra, India; ${ }^{3}$ nstitute of Bioinformatics and Biotechnology, Savitribai Phule Pune University, Pune 411007, Maharashtra, India; “Behavioural Intervention for Lifestyle Disorders (BILD) Clinic, Deenanath Mangeshkar Hospital and Research Centre, Erandwane, Pune 411004, Maharashtra, India.

*Correspondence: Neelesh Dahanukar, n.dahanukar@iiserpune.ac.in

Keywords: bacterial predation; antibiotic production; secondary metabolites; enzyme inhibition; molecular phylogeny.

Abbreviations: ACE, angiotensin-converting enzyme; bPTP, Poisson tree processes with Bayesian partitioning; MCC, microbial culture collection; mPTP, Poisson tree processes with maximum-likelihood partitioning; NCIM, National Collection of Industrial Microorganisms; PRS, poor ravan saline; ZMB, ZoBbell Mmarine broth.

GenBank accession numbers: MN339687-MN339897 and MT598037-MT598065.

Two supplementary tables are available with the online version of this article. $000242 \odot 2021$ The Authors 
cocci to highly differentiated mycelia [20]. Marine ecosystems are believed to have a wide range of unexplored actinobacteria [21] and their metabolites [2, 3, 22], with diverse biological activities such as anticancer [23], anti-inflammatory [24], antibiotic [25-27], cytotoxic [28] and enzyme inhibitory $[29,30]$ activity. Watve et al. [31] estimated that the genus Streptomyces alone is capable of producing up to $10^{5}$ different metabolites, the majority of which remain unexplored. Of 23000 medicinally important metabolites produced by marine micro-organisms, $70 \%$ are contributed by actinobacteria [32]. To date, 8 Actinobacteria genera have been reported to produce secondary metabolites and 267 products have been reported from 96 marine actinobacteria [33].

Ecologically, it is difficult to understand the production of extracellular metabolites or enzymes by aquatic bacteria, since any molecule secreted outside the cell can be quickly washed off $[34,35]$. Extracellular products could be useful to the producer only in viscous or partially enclosed environments. In the marine environment, sponges are likely to provide such a closed environment for bacteria. Sponges are filter feeders and collect small nutrient particles, including bacteria. This makes the environment locally nutrient-rich in otherwise oligotrophic surroundings. Bacteria, especially actinobacteria, isolated from these sponges may live in a symbiotic relationship that helps the host with defence against predation, sponge skeleton stabilization, translocation of metabolites and the nutritional process $[2,17,21,25-27,36,37]$. In addition, since sponges are sessile and lack other anti-predator defences, secondary metabolites of bacteria can provide them with chemical defence [38]. Therefore, we expect more secondary metabolite related activities from spongeassociated actinobacteria.

Sponge-associated actinobacteria are likely to have another ecological role. In the phylum Actinobacteria, at least three genera, namely Agromyces, Streptomyces and Streptoverticillium, have been shown to be predators that kill and feed on other live bacterial cells [39-42]. Kumbhar and Watve [34] argued that antibiotic activity might have evolved primarily as a weapon in predation. However, the expression of secondary metabolites during predation may be independent of antibiotic expression in pure culture; the latter is likely to have evolved for mutualism with higher animal or plant hosts $[43,44]$. We hypothesize that, for a niche of predation in association with sponge, the predatory actinobacterial species need to protect themselves from the digestive enzymes of the sponge as well as their own enzymes used for predation. Therefore, predatory actinobacteria are also expected to have efficient inhibitors of lytic enzymes.

The northern parts of the western coast of India, along the Arabian sea, include the coastal regions of the states of Maharashtra and Goa and span approximately $880 \mathrm{~km}$. The climate of this region is humid tropical and it receives extensive rainfall during the monsoon season. Within the coastal zone there are a number of critical habitats, including estuaries, lagoons, mangroves, coral reefs, seagrass beds, tidal mudflats, backwaters, salt marshes, rocky coasts, sandy stretches and oceanic islands [45], which harbour a rich diversity of biota, including coral reefs [46] and mangrove forests [47]. However, studies on the microbial diversity of this region are scarce $[8,48]$.

In this study, we prepared an inventory of cultivable actinobacteria from sponges and associated environments of the intertidal zones along the northern parts of the western coast of India and studied their molecular diversity based on $16 \mathrm{~S}$ rRNA gene sequences. We screened a subset of randomly selected cultures for predatory activity, antibiotic production and enzyme inhibition, and tested their associations with each other and with the isolation source to test the hypotheses mentioned earlier.

\section{METHODS \\ Sample collection}

Small tissue samples $(<1 \mathrm{~g})$ of marine sponges (Haliclona spp.) were collected at low tide along the Maharashtrian and Goan coast $\left(18-15^{\circ} \mathrm{N}\right.$ and $\left.73-74^{\circ} \mathrm{E}\right)$ of India during April 2014 to October 2018 without damaging the sponge or its associated environment. Specimens were rinsed and flushed with sterile distilled water using a dropper multiple times to remove debris and loosely attached microbes without damaging the tissue. Each sponge sample was collected in labelled polystyrene tubes with lids containing sterile poor Ravan saline (PRS) [49] and Zobell marine broth (ZMB) (Table 1)) [50]. Sediment, water and air samples were collected from the same environment as that of the sponge and were collectively considered as environmental samples. Sediment samples were collected directly inside sterile polypropylene tubes by immersing the tubes at the bottom of the rocky pool. Air samples were collected as a control to ensure that the isolates obtained from sponge, sediment or water were not air contaminants. For air sample collection, sterile polypropylene tubes containing sterile media were exposed to the air around the sampling spots. The samples were brought to the laboratory maintaining cold chain and were immediately processed for microbial culturing.

\section{Isolation and maintenance of cultivable actinobacteria}

Sediment samples were subjected to pre-heat treatment at $60^{\circ} \mathrm{C}$ for $15 \mathrm{~min}$ to reduce the numbers of Gram-negative bacteria commonly found in marine samples, which often overcrowd the isolation plate [51]. Sediment samples vortexed in sterile saline were allowed to settle and supernatant was serially diluted up to $10^{-5}$. Samples $(0.1 \mathrm{ml})$ were spread into triplicates on Petri plates containing sterile medium. Similarly, dilutions of the water samples were also plated. Sponge tissue $\left(0.1 \mathrm{~cm}^{3}\right)$ was homogenized in sterile saline and vortexed for $5 \mathrm{~min}$. Tubes were left undisturbed for $2 \mathrm{~min}$. From the resulting supernatant, serial 10 -fold dilutions up to $10^{-5}$ were made and $0.1 \mathrm{ml}$ samples were spread in triplicates on Petri plates containing sterile medium. We used two solid media, Zobell Marine Agar (ZMA) and poor Ravan saline agar (PRSA) (Table 1), with and without the antibiotic chloramphenicol $\left(25 \mu \mathrm{g} \mathrm{ml}^{-1}\right)$. 
Table 1. Composition of poor Ravan saline (PRS) and Zobell marine broth (ZMB)

\begin{tabular}{|c|c|c|}
\hline Medium & Ingredients & $\begin{array}{c}\text { Concentration } \\
\left(\mathrm{g}^{-1}\right)\end{array}$ \\
\hline \multirow[t]{6}{*}{ Poor Ravan saline } & Glucose & 0.050 \\
\hline & Peptone, & 0.050 \\
\hline & Yeast extract & 0.050 \\
\hline & Sodium acetate & 0.050 \\
\hline & Sodium citrate & 0.050 \\
\hline & Pyruvic acid & 0.050 \\
\hline \multirow{16}{*}{$\begin{array}{l}\text { Zobell marine } \\
\text { broth }^{*} \dagger\end{array}$} & Peptone & 5.000 \\
\hline & Yeast extract & 1.000 \\
\hline & Ferric citrate & 0.100 \\
\hline & Sodium chloride & 19.450 \\
\hline & Magnesium chloride & 8.800 \\
\hline & Sodium sulphate & 3.240 \\
\hline & Calcium chloride & 1.800 \\
\hline & Potassium chloride & 0.550 \\
\hline & Sodium bicarbonate & 0.160 \\
\hline & Potassium bromide & 0.080 \\
\hline & Strontium chloride & 0.034 \\
\hline & Boric acid & 0.022 \\
\hline & Sodium silicate & 0.004 \\
\hline & Sodium fluorate & 0.003 \\
\hline & Ammonium nitrate & 0.002 \\
\hline & Disodium phosphate & 0.008 \\
\hline $\begin{array}{l}\text { *Solid media cont } \\
\text { †Final pH } 7.6 \pm 0.2\end{array}$ & $5 \mathrm{~g} \mathrm{l}^{-1}$ of agar. & \\
\hline
\end{tabular}

Antibiotic producers are known to harbour the most antibiotic resistance genes [52]; therefore, use of a broadspectrum antibiotic is expected to enhance selective isolation of antibiotic-rich organisms. Chloramphenicol was used as a broad-spectrum antibiotic for this purpose. Plates were incubated at $30^{\circ} \mathrm{C}$ for 7 days in the case of ZMA and 21 days for PRSA. Plates were observed regularly for the growth of actinobacteria. Bacterial colonies that showed resemblance to actinobacteria under a light microscope were purified four-five times on respective media to ensure axenic culture. In all, 237 actinobacterial isolates were selected and were restreaked to make pure cultures. Colonies were labelled as per the Maharashtra Gene Bank (MGB) project code and preserved on ZMA slants at $4{ }^{\circ} \mathrm{C}$ for further use. Similarly, glycerol (18\%) stocks were prepared and maintained at $-20^{\circ} \mathrm{C}$ for long-term storage. Actinobacterial cultures were deposited in the Microbial Culture Collection (MCC) of the National Centre for Microbial
Resource, National Centre for Cell Sciences, Pune, India (accession numbers are provided in Table S1, available in the online version of this article).

\section{Genetic identification, phylogeny and species delimitation}

Actinobacterial genomic DNA was extracted using the Wizard Genomic DNA Purification kit (Promega, USA) following the manufacturer's protocols. The full-length $(1.5 \mathrm{~kb}) 16 \mathrm{~S}$ rRNA gene was amplified using polymerase chain reaction (PCR) with universal primers $27 \mathrm{~F}\left(5^{\prime}-\mathrm{AGA}\right.$ GTT TGA TCM TGG CTC AG-3') and 1492R (5'-TAC GGY TAC CTT GTT ACG ACT T-3') [53]. PCR was performed on the total reaction volume of $25 \mu \mathrm{l}$ containing $5 \mu \mathrm{l}$ template DNA ( $200 \mathrm{ng}), 2.5 \mu \mathrm{l}$ of $10 \times$ reaction buffer (100 mM Tris pH 9.0, $500 \mathrm{mM} \mathrm{KCl}, 15 \mathrm{mM} \mathrm{MgCl}, 0.1 \%$ gelatin), $1 \mu \mathrm{l}$ of $10 \mathrm{mM}$ dNTPs, $1 \mu \mathrm{l}$ of each $5 \mu \mathrm{M}$ primer and

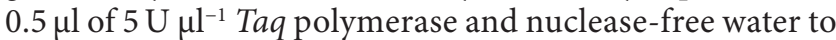
make up the final volume. The thermal profile was $2 \mathrm{~min}$ at $94^{\circ} \mathrm{C}$, and 25 cycles of $10 \mathrm{~s}$ at $98^{\circ} \mathrm{C}, 30 \mathrm{~s}$ at $53^{\circ} \mathrm{C}$ and $1 \mathrm{~min}$ at $68^{\circ} \mathrm{C}$, followed by an extension of $10 \mathrm{~min}$ at $68^{\circ} \mathrm{C}$. Amplified DNA fragments were purified using the Wizard Gel and PCR clean up (Promega, USA) system and sequenced bidirectionally using the BigDye Terminator v3.1 Cycle Sequencing kit (Applied Biosystems). Chromatograms of the sequences were manually checked for quality using BioEdit [54]. Forward and reverse sequences were assembled to form the complete 16S rRNA gene using GeneStudio sequence analysis software version 2.2.0.0 (GeneStudio, Suwanee, GA, USA; http://www.genestudio.com/).

The gene sequences used for the study were deposited in the GenBank database under the accession numbers MN339687-MN339897 and MT598037-MT598065 (Table S1). Sequences were checked in BLAst [55] to find the closest sequences available in the GenBank database (http://www.ncbi.nlm.nih.gov). Four species of Firmicutes, namely Bacillus paralicheniformis (MCC 6306), Bacillus thuringiensis (MCC 7835), Bacillus subtilis (MCC 6386) and Bacillus halotolerans (MCC 8381), were used as outgroups (GenBank accession numbers MN339894-MN339897, respectively).

Gene sequences were aligned using MUSCLE [56] implemented in MEGA 7 [57]. The final aligned matrix had 1595 sites. The best nucleotide substitution model was determined using ModelFinder [58] based on the Bayesian information criterion $[59,60]$. Maximum-likelihood analysis was performed in IQ-TREE [61] with ultrafast bootstrap support [62] for 1000 iterations. The phylogenetic tree was edited in FigTree v1.4.2 [63].

To understand the putative number of actinobacterial species we performed species delimitation based on Poisson tree processes [64] with maximum-likelihood partitioning (mPTP) and Bayesian partitioning (bPTP). A maximumlikelihood tree was used to delimit species by setting the parameter values as follows: MCMC generations $=100000$, thinning $=100$, burn-in $=0.1$ and seed $=123$. 


\section{Screening for activities}

Out of 237 actinobacterial isolates, 50 isolates were selected randomly for the screening of 3 activities, namely predation, antibiotic production and production of enzyme inhibition.

\section{Target bacteria used for predation and antibiotic screening}

Test bacteria of clinical importance, used for checking actinobacterial predation and antibiotic production, were obtained from MCC and National Collection of Industrial Microorganisms (NCIM), National Chemistry Laboratory, Pune, India. Fourteen bacteria, namely Acetobacter pasterianus (NCIM 2317), Alcaligenes fecalis (NCIM 2262), B. subtilis (NCIM 2063), Enterococcus fecalis (MCC 6462), Escherichia coli (NCIM 2184), Klebsiella pneumonae (NCIM 2957), Micrococcus luteus (NCIM 2673), Mycobacterium smegmatis (NCIM 5138), Proteus vulgaris (NCIM 2172), Pseudominas aeruginosa (NCIM 5029), Salinicoccus roseus (MCC 7574), Salmonella enterica (NCIM 2501), Serretia marcescens (NCIM 2919) and Staphylococcus aureus (NCIM 2121), were used as target species for screening.

\section{Screening for actinobacterial predatory growth}

The growth of predators with the zone of clearance on prey cells was considered as predation as defined earlier [41]. The method for the preparation of prey cells was modified from Kumbhar et al. [41] and Pund et al. [42]. Pure cultures of the prey species were inoculated on nutrient agar plates to check the purity and were later reinoculated in nutrient broth. Inoculated flasks were incubated at $37^{\circ} \mathrm{C}$ for $24 \mathrm{~h}$. Broth culture was centrifuged at $6026 \mathrm{~g}$ for $10 \mathrm{~min}$ to concentrate cells using the Eppendorf centrifuge 5810R. Cells were washed thrice with sterile distilled water to remove traces of nutrient broth. Pellets were suspended in saline to obtain a thick suspension with an optical density of 1.0 at $600 \mathrm{~nm}$. A lawn of prey cells $(0.1 \mathrm{ml})$ was spread on water agarose plates and plates were incubated at $37^{\circ} \mathrm{C}$ for $40 \mathrm{~min}$. Fresh actinobacterial culture was spot inoculated on preincubated plates. These plates were incubated at for $48-72 \mathrm{~h}$ at $30^{\circ} \mathrm{C}$. Plates with plaques were examined visually and by using 4 and $45 \times$ magnification under a light microscope. Prey and predator control plates were used for comparison. Each experiment consisted of triplicate sets of plates, as well as one predator control for testing the growth of an actinobacterial predator without prey. In addition, there was a prey control to demonstrate viable and independent growth of prey without a predator. In either control there was no zone of clearance, indicating that there was no predation in the presence of predator or prey alone.

\section{Screening for antibacterial activity using the conventional cross-streak method}

Selected actinobacterial cultures were screened for antibacterial activity using the cross-streak method $[65,66]$.
The test organism was streaked as a straight line along the diagonal of the Petri dish with sterile ZMA medium. The isolated pure colony of actinobacteria was inoculated as a single streak perpendicular to the central streak. Streaking was done from the edge of the plate to the test organism growth line. Plates were incubated at $37^{\circ} \mathrm{C}$ for $18 \mathrm{~h}$. The microbial inhibition was observed by determining the zone of clearance around the sensitive organisms. Inhibition activity was recorded qualitatively as presence or absence. Control plates of the same medium with the streak of test bacteria and without the streak of actinobacteria growth were used to observe the normal growth of the test bacteria.

\section{Screening for enzyme inhibitors}

Actinobacterial cultures were screened for their ability to inhibit the activity of serine proteases and angiotensinconverting enzyme (ACE). Inhibition of serine proteases was selected to test our hypothesis that predatory actinobacteria will have efficient inhibitors of lytic enzymes, while ACE inhibition was selected because it has clinical applications. Three different serine proteases, i.e. subtilisin, trypsin and $\alpha$-chymotrypsin, were used to screen for inhibitory activity. Protease inhibitor activity was studied using unprocessed X-ray films and the spot test method [67] with modifications. As described by Tripathi et al. [68], dilutions of pure enzyme were first spotted on gelatine-coated films. The lowest dilution showing complete clearance (indicating complete digestion of gelatine) was chosen for further studies. Pure enzyme $\left(100 \mu \mathrm{g} \mathrm{ml}^{-1}\right)$ was incubated with an equal volume of cell-free supernatant of actinobacterial isolates (10 $\mu \mathrm{l} \mathrm{each)} \mathrm{for} 10 \mathrm{~min}$ and transferred to untreated $\mathrm{X}$-ray-Fuji Medical X-ray HRU grade films. The mixtures were allowed to react for $15 \mathrm{~min}$ at room temperature and the results were recorded after the X-ray films were washed under running water. Unprocessed X-ray films contain a layer of gelatine on their surface, which acts as a substrate for various proteolytic enzymes. Degradation of gelatine gives a clear zone at the site of activity. Thus, upon the action of the proteases, clear zones were seen on unprocessed X-ray films, at the site of inoculation, whereas, if the gelatine layer remained intact, no clearance was observed. No clearance on the films indicated the presence of protease inhibitors.

ACE acts on a specific substrate N-hyppuryl-His-Leu (HHL) to liberate hippuric acid and His-Leu. Liberated hippuric acid was detected spectrophotometrically. Upon reaction of the enzyme with ACE inhibitors, the enzyme becomes inactive and this is measured in terms of lower levels of hippuric acid being released. The protocol suggested by Cushman and Cheung [69] was used with certain modifications and hippuric acid liberation was checked using the method suggested by $\mathrm{Ng}$ et al. [70]. Equal volumes of ACE $\left(100 \mu \mathrm{g} \mathrm{ml}^{-1}\right)$ and cell-free supernatants $(10 \mu \mathrm{l} \mathrm{each})$ were allowed to react at $37^{\circ} \mathrm{C}$. After $10 \mathrm{~min} 20 \mu \mathrm{l}$ of HHL was added to the reaction mixture and the reaction was continued for $30 \mathrm{~min}$ at $37^{\circ} \mathrm{C}$. The reaction was stopped 
by the addition of $40 \mu \mathrm{l}$ of $1 \mathrm{~N} \mathrm{HCl}$. A blank was prepared by the addition of $\mathrm{HCl}$ before the addition of the substrate. A positive enzyme control was prepared by incubating enzyme with uninoculated broth. Liberated hippuric acid was extracted in $90 \mu \mathrm{l}$ ethyl acetate by vigorous shaking. The ethyl acetate layer was collected in a fresh vial and allowed to dry in a water bath at $50^{\circ} \mathrm{C}$. The liberated hippuric acid was diluted in $150 \mu \mathrm{l}$ distilled water and absorbance was checked at $228 \mathrm{~nm}$. Zero was adjusted using distilled water. Test vials with more than $15 \%$ inhibition of ACE were considered to be positive for ACE inhibitor.

\section{Statistical analysis}

Association between the source of isolation and the frequency of occurrence of three activities (predation, antibiosis and enzyme inhibition) and association between the frequency of occurrence of different activities was tested using the $\chi^{2}$ test of association with the null hypothesis that there is no significant association. The null hypothesis that there was no significant difference in the frequency of actinobacterial isolated that showed antibiosis or predatory activity against Gram-negative and Gram-positive test organism was tested using the Mann-Whitney U test. All statistical tests were evaluated at $\alpha=0.05$. Statistical tests were performed using the freeware PAST 4.0 [71].

\section{RESULTS}

\section{Actinobacterial phylogenetic diversity in sponge and associated environments}

The phylogenetic diversity of actinobacteria from sponges and associated environments is shown in Fig. 1. We obtained 237 actinobacterial isolates, from sponge and associated environments, belonging to 19 families and 28 genera (Table S1). Species delimitation based on MPTP suggested that these isolates belong to 95 putative species, while bPTP suggested 100 putative species. The two species delimitation methods, $\mathrm{mPTP}$ and bPTP, differed in the groups of species under the genera Micrococcus, Rhodococcus and Streptomyces (Table $\mathrm{S} 1)$. We only recovered 3 isolates from air, belonging to the genera Brachybacterium, Brevibacterium and Rhodococcus, as compared to 39 isolates from water, 105 isolates from sediment and 90 isolates from sponge, suggesting that the isolates from water, sediment and sponge were not due to air contamination.

From sponges, there were 18 genera under 14 families belonging to 56 putative species (Table 2). From the spongeassociated environment, 22 genera under 15 families were recorded belonging to 64 putative species as per $\mathrm{MPTP}$ and 65 putative species as per bPTP. A total of 12 genera under 9 families and 28 putative species based on $\mathrm{MPTP}$ and 25 putative species based on bPTP were common to both sponges and their associated environments.

Six genera, namely Gordonia, Jonesia, Mycolicibacterium, Pseudonocardia, Rothia and Serinicoccus, were isolated only from sponges (Tables 2 and S1), which could be identified as species Gordonia terrae (MCC 6452), Jonesia denitrificans (MCC 7852), Mycolicibacterium poriferae (MCC 6242), Pseudonocardia kongjuensis (MCC 7930) and Rothia terrae (MCC 7823) and Serinicoccus marinus (MCC 7935), respectively. Although 12 genera, namely Agrococcus, Arthrobacter, Brachybacterium, Brevibacterium, Klenkia, Kocuria, Microbacterium, Micrococcus, Micromonospora, Nocardiopsis, Rhodococcus and Streptomyces, were isolated from both sponges and associated habitats, most of these genera had some putative species that were exclusive to either sponges or associated environments. In particular, seven species, Brachybacterium muris (MCC 7614), Brevibacterium casei (MCC 6140, MCC 6152, MCC 6176), Kocuria rhizophila (MCC 8384), Nocardiopsis salina (MCC 7931), Rhodococcus zopfii (MCC 7934), Streptomyces smyrnaeus (MCC 7924) and Streptomyces viridobrunneus (MCC 7990), were recorded only from sponges.

With respect to both the number of isolates and the number of putative species, Streptomyces was the most dominant genus, and was found in both sponges and associated environments. Nocardiopsis was the second most common genus, with two dominant species Nocardiopsis alba (MCC 8385) followed by Nocardiopsis dassonvillei (MCC 7845). Among the genera and species that were only recorded from the environment, we provide the first record of species such as Aeromicrobium massiliense (MCC 6739) and Glutamicibacter mysorens (MCC 7825) from marine waters.

\section{Non-obligate epibiotic predatory activity}

Out of the total of 50 actinobacterial isolates screened for non-obligate epibiotic predatory activity, 26 isolates showed predation against at least 1 of the 14 target organisms (Table S2). Of the 26 isolates with predatory behaviour, 17 preyed on Gram-negative prey, 21 preyed on Gram-positive prey, and 12 preyed on both Gram-negative and Gram-positive prey. There was no significant difference (Mann-Whitney $U=15$, $P=0.2601)$ in the frequency of actinobacterial predators on Gram-negative and Gram-positive prey (Table 3). Most actinobacterial predators $(n=14)$ preyed on a single prey species, while only a few predators preyed on multiple prey species. A single predator of the genus Streptomyces preyed on eight prey species. There was a significant association between the source of isolation (sponge or associated environment) and predatory behaviour $\left(\chi^{2}=5265, P=0.0218\right)$, where the isolates from sponge showed proportionately more predatory behaviour (Fig. 2).

All eight isolates of Streptomyces used for screening showed predatory behaviour and preyed on both Gram-negative and Gram-positive prey (Table S2). Out of 25 isolates of Nocardiopsis, 12 showed predatory behaviour, out of which 5 preyed on Gram-negative bacteria while 11 preyed on Gram-positive bacteria. Both Micromonospora isolates preyed on Grampositive prey, while only one preyed on Gram-negative prey. Isolates belonging to the genera Brevibacterium, Glutamicibacter and Rhodococcus only preyed on Gram-negative prey, while Rothia only preyed on Gram-positive prey. 


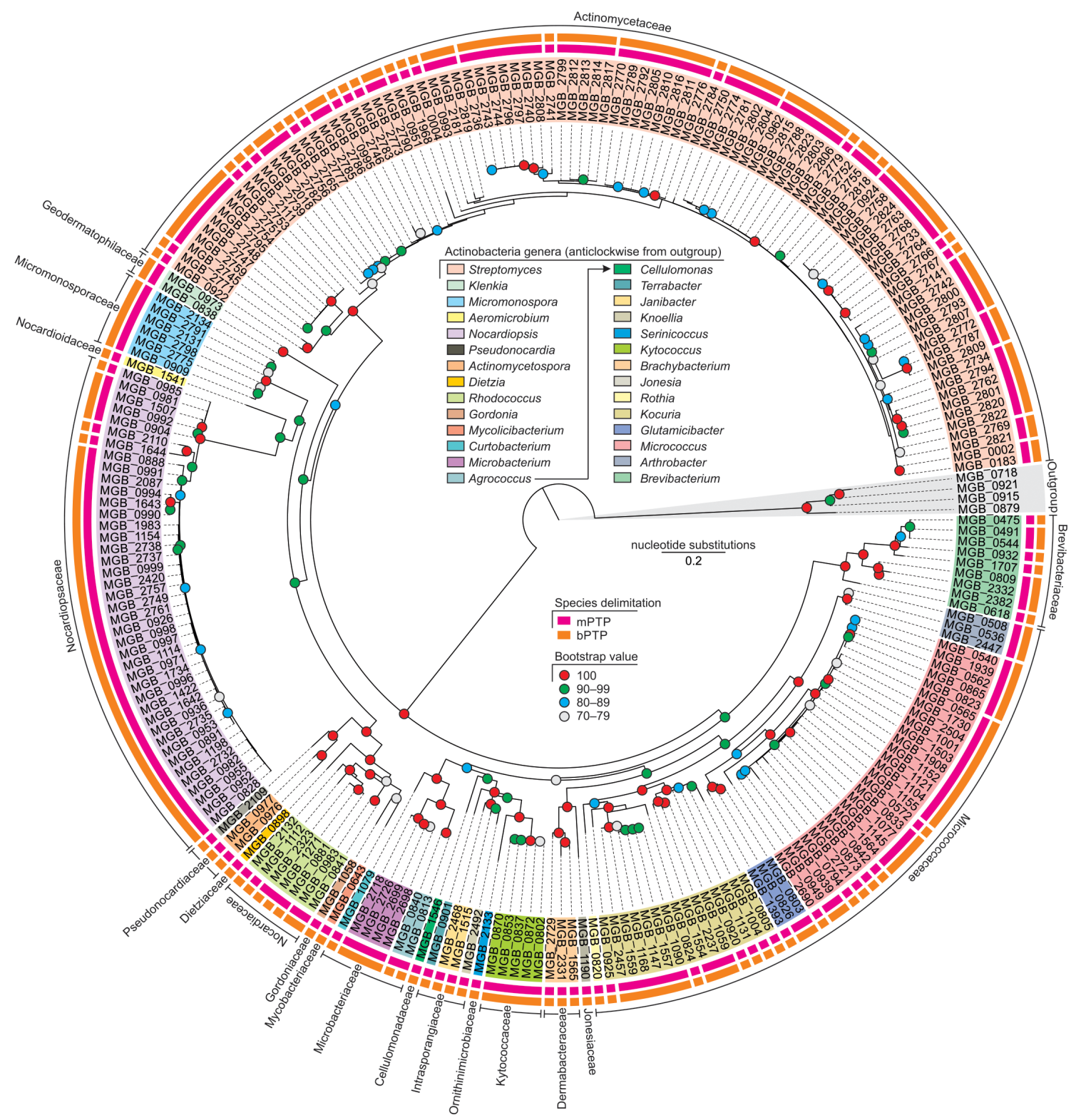

Fig. 1. Maximum-likelihood phylogenetic tree of actinobacterial isolates based on the TIM3+F+I+G4 nucleotide substitution model (InL of consensus tree: -18 684.58). Firmicutes belonging to genus Bacillus were used as outgroups.

\section{Antibiosis, antibacterial activity and growth inhibition}

Of the 50 actinobacterial isolates screened for antibacterial activity, 25 showed antibiosis against at least 1 target organism (Table S2). Of these 25 isolates, all showed antibiosis against at least 1 of the Gram-positive target species, while only 5 showed antibiosis against at least 1 of the Gram-negative organisms. The frequency of antibacterial activity against Gram-positive organisms was significantly higher (MannWhitney $\mathrm{U}=1.5, P=0.003)$ than against Gram-negative organisms (Table 3). Most antibacterial activities were broad spectrum with respect to the target organisms that they affected. There were 10 actinobacterial isolates that showed antibiosis against 2 target organisms, 6 isolates that affected 4 target species and 2 isolates that affected 6 target species. There was no association between antibacterial activity and the source (sponge or associated environment) of the isolation $\left(\chi^{2}=2.0129, P=0.1560\right)$.

Out of eight Streptomyces isolates that were screened for antibacterial activity, five showed antibiosis, of which two showed antibiosis against Gram-negative target species, while all showed antibiosis against Gram-positive organisms. In the case of Nocardiopsis, of the 25 isolates used for screening, 17 showed antibiosis, of which all affected the growth of Gram-positive organisms, while only 2 affected the growth 
Table 2. Putative number of species of actinobacterial genera based on mPTP and bPTP methods isolated from sponge, associated environments and both sources

\begin{tabular}{|c|c|c|c|c|c|c|c|}
\hline Family & Genus & \multicolumn{2}{|c|}{ Sponge } & \multicolumn{2}{|c|}{ Environment } & \multicolumn{2}{|c|}{ Both } \\
\hline Actinomycetaceae & Streptomyces & 23 & 23 & 24 & 25 & 12 & 11 \\
\hline Brevibacteriaceae & Brevibacterium & 5 & 5 & 2 & 2 & 1 & 1 \\
\hline Cellulomonadaceae & Cellulomonas & 0 & 0 & 1 & 1 & 0 & 0 \\
\hline Dietziaceae & Dietzia & 0 & 0 & 1 & 1 & 0 & 0 \\
\hline Geodermatophilaceae & Klenkia & 1 & 1 & 1 & 1 & 1 & 1 \\
\hline Gordoniaceae & Gordonia & 1 & 1 & 0 & 0 & 0 & 0 \\
\hline Intrasporangiaceae & Janibacter & 0 & 0 & 2 & 2 & 0 & 0 \\
\hline Jonesiaceae & Jonesia & 1 & 1 & 0 & 0 & 0 & 0 \\
\hline Kytococcaceae & Kytococcus & 0 & 0 & 1 & 1 & 0 & 0 \\
\hline \multirow[t]{3}{*}{ Microbacteriaceae } & Agrococcus & 1 & 1 & 1 & 1 & 1 & 0 \\
\hline & Curtobacterium & 0 & 0 & 1 & 1 & 0 & 0 \\
\hline & Microbacterium & 1 & 1 & 1 & 1 & 1 & 1 \\
\hline \multirow[t]{3}{*}{ Micrococcaceae } & Arthrobacter & 1 & 1 & 1 & 1 & 1 & 1 \\
\hline & Glutamicibacter & 0 & 0 & 2 & 2 & 0 & 0 \\
\hline & Kocuria & 4 & 4 & 6 & 6 & 2 & 2 \\
\hline Nocardioidaceae & Aeromicrobium & 0 & 0 & 1 & 1 & 0 & 0 \\
\hline Nocardiopsaceae & Nocardiopsis & 4 & 4 & 3 & 3 & 2 & 2 \\
\hline Ornithinimicrobiaceae & Serinicoccus & 1 & 1 & 0 & 0 & 0 & 0 \\
\hline \multirow[t]{3}{*}{ Pseudonocardiaceae } & Actinomycetospora & 0 & 0 & 1 & 1 & 0 & 0 \\
\hline & Pseudonocardia & 1 & 1 & 0 & 0 & 0 & 0 \\
\hline & Total & 56 & 56 & 64 & 65 & 28 & 25 \\
\hline
\end{tabular}

of Gram-negative organisms. Genus Kytococcus showed antibiosis that affected both Gram-positive and Gram-negative organisms, while Glutamicibacter and Rothia only showed antibiosis against Gram-positive organisms.

\section{Enzyme inhibition}

Out of 50 actinobacterial isolates screened for the inhibition of 4 enzymes, 30 isolates inhibited at least 1 of the enzymes
(Table S2). Of these 30 isolates, 28 inhibited trypsin, 24 inhibited chymotrypsin, 3 inhibited angiotensin-converting enzyme (ACE) and only 2 inhibited subtilisin. A Venn diagram of the frequency of isolates inhibiting different enzymes (Fig. 3) suggested that five isolates only inhibited trypsin and one isolate each inhibited chymotrypsin and ACE, while subtilisin inhibition was accompanied by the inhibition of other enzymes. No isolate inhibited all four enzymes. Out of 30 actinobacteria that produced enzyme 
Table 3. Predation and antibiotic production by actinobacteria against the Gram-positive and Gram-negative target species

\begin{tabular}{|c|c|c|c|}
\hline Target species & Predation & Antibiotic & $\begin{array}{l}\text { Predation and } \\
\text { antibiotic by same } \\
\text { actinobacterial } \\
\text { isolate }\end{array}$ \\
\hline \multicolumn{4}{|l|}{ Gram-positive } \\
\hline $\begin{array}{l}\text { Mycobacterium } \\
\text { smegmatis }\end{array}$ & 3 & 12 & 0 \\
\hline Micrococcus luteus & 8 & 5 & 0 \\
\hline Bacillus subtilis & 1 & 24 & 1 \\
\hline Staphylococcus aureus & 17 & 9 & 4 \\
\hline Salinicoccus roseus & 9 & 3 & 0 \\
\hline Enterococcus faecalis & 3 & 20 & 1 \\
\hline \multicolumn{4}{|l|}{ Gram-negative } \\
\hline $\begin{array}{l}\text { Acetobacter } \\
\text { pasterianus }\end{array}$ & 7 & 0 & 0 \\
\hline Alcaligenes faecalis & 3 & 1 & 1 \\
\hline Escherichia coli & 2 & 5 & 0 \\
\hline Klebsiella pneumoniae & 3 & 0 & 0 \\
\hline Proteus vulgaris & 8 & 0 & 0 \\
\hline Salmonella enterica & 2 & 0 & 0 \\
\hline Serratia marcescens & 3 & 0 & 0 \\
\hline $\begin{array}{l}\text { Pseudomonas } \\
\text { aeruginosa }\end{array}$ & 1 & 0 & 0 \\
\hline
\end{tabular}

inhibitors, 19 produced 2 inhibitors, 4 produced 3 inhibitors and 7 produced only one of the 4 inhibitors. There was no association between enzyme inhibition and the source of the actinobacterial isolate $\left(\chi^{2}=2.3386, P=0.1262\right)$.

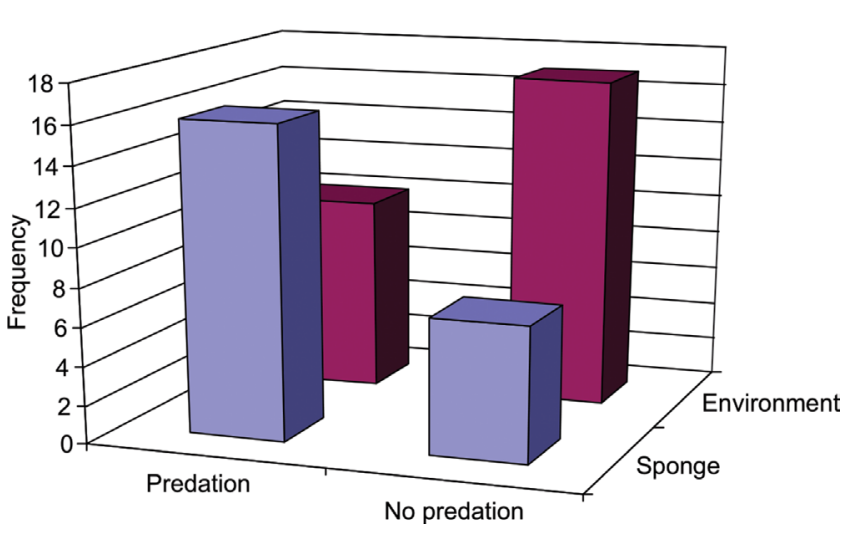

Fig. 2. Association between source of actinobacterial isolation and predatory behaviour. There was a significant association between the source (sponge or associated environment) of actinobacterial isolation and predation $\left(\chi^{2}=5.265, P=0.0218\right)$.

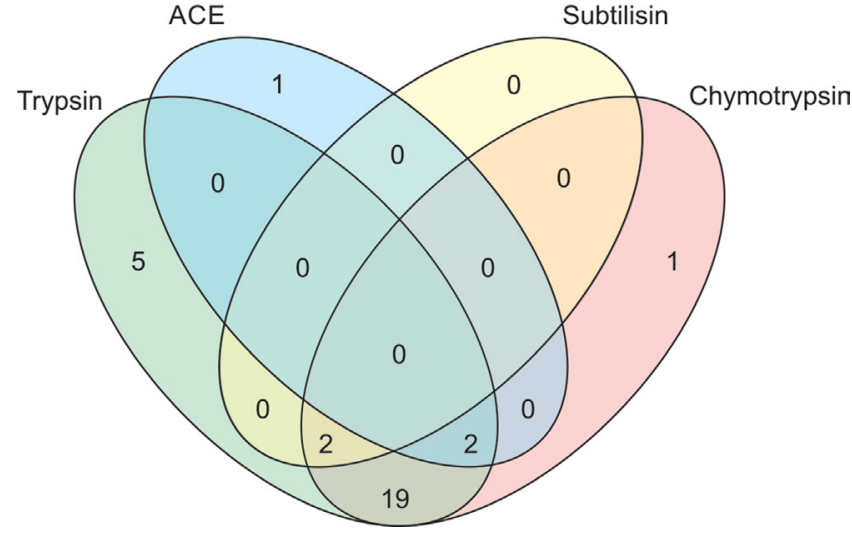

Fig. 3. Venn diagram combination of enzyme inhibitors produced by actinobacterial isolates. Venn diagram is not to scale.

Out of 8 isolates of Streptomyces, 7 produced enzyme inhibitors against proteases, while 12 out of 25 isolates of Nocardiopsis produced enzyme inhibitors, of which 11 worked against proteases and 2 worked against ACE (Table 4). One isolate of Actinomycetospora inhibited the activity of ACE.

\section{Associations between different activities}

Out of 50 actinobacterial isolates that were screened for activities, 39 showed at least 1 of the 3 activities. Of these 39 isolates, 15 showed all 3 activities, while 9 showed predation as well as enzyme inhibition (Fig. 4). There were only seven isolates that showed predation and antibiotic production against the same target organism (Table 3) and all of these isolates belonged to the genera Streptomyces and Nocardiopsis.

Antibiotic production showed no significant association with predation $\left(\chi^{2}=2.8846, P=0.0894\right)$ or inhibition of any of the four enzymes $\left(\chi^{2}=2.0525, P=0.1520\right)$. However, there were significant associations between predation and protease inhibitors (Fig. 5). Twenty-four isolates showed both predation and inhibition of at least one enzyme, and there was a significant association between the two activities $\left(\chi^{2}=26.172\right.$, $P<0.0001$ ), where predators produced proportionally more enzyme inhibitors than non-predators (Fig. 5a). Twenty-three actinobacterial isolates showed both predation and trypsin inhibition, and there was a significant association between the two $\left(\chi^{2}=23.165, P<0.0001\right)$, with predators more likely to produce trypsin inhibitors than non-predators (Fig. 5b). Similarly, 24 actinobacteria were predatorsand inhibited chymotrypsin activity, and there was a significant association between the two $\left(\chi^{2}=42.604, P<0.0001\right)$, with predators more likely to produce chymotrypsin inhibitors than non-predators (Fig. 5c).

\section{DISCUSSION}

Sponges and associated environments in the northern parts of the western coast of India are rich in actinobacterial diversity, with $\sim 95$ putative species under 19 families and 28 genera. 
Table 4. Frequency of actinobacterial isolates producing four different enzyme inhibitors

\begin{tabular}{|c|c|c|c|c|c|c|}
\hline Genus & No. of isolates & \multicolumn{4}{|c|}{ Frequency of isolates inhibiting } & Isolates with at least one inhibition activity \\
\hline Actinomycetospora & 2 & 0 & 1 & 0 & 1 & 2 \\
\hline Agrococcus & 1 & 0 & 0 & 0 & 0 & 0 \\
\hline Brevibacterium & 1 & 0 & 1 & 1 & 0 & 1 \\
\hline Jonesia & 1 & 0 & 0 & 0 & 0 & 0 \\
\hline Kocuria & 1 & 0 & 0 & 0 & 0 & 0 \\
\hline Kytococcus & 1 & 0 & 1 & 0 & 0 & 1 \\
\hline Micrococcus & 1 & 0 & 1 & 0 & 0 & 1 \\
\hline Pseudonocardia & 1 & 0 & 0 & 0 & 0 & 0 \\
\hline Rhodococcus & 4 & 0 & 2 & 1 & 0 & 2 \\
\hline Rothia & 1 & 0 & 1 & 1 & 0 & 1 \\
\hline Streptomyces & 8 & 2 & 7 & 7 & 0 & 7 \\
\hline
\end{tabular}

We recorded 13 species of actinobacteria solely from sponges. Of these, Mycobacterium poriferae was originally described from marine sponge [72], while three species, Gordonia terrae [21, 73, 74], Brevibacterium casei [75] and Kocuria rhizophila

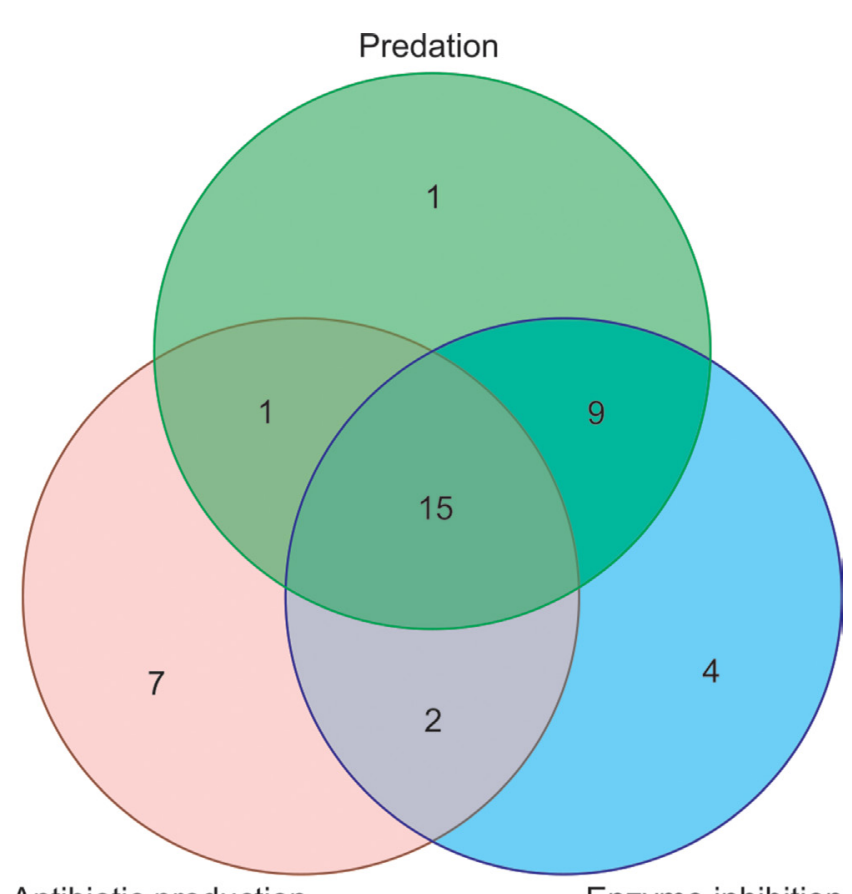

Antibiotic production

Enzyme inhibition

Fig. 4. Venn diagram of predation, antibiotic production and enzyme inhibition by actinobacterial isolates. Venn diagram is not to scale.
[76], have previously been reported from sponges. To our knowledge, we provide the first report of nine species, namely Brachybacterium murisi, Jonesia denitrificans, Nocardiopsis salina, Pseudonocardia kongjuensis, Rhodococcus zopfii, Rothia terrae, Serinicoccus marinus, Streptomyces smyrnaeus and Streptomyces viridobrunneus, from marine sponges, although some of them are known from marine habitats [77-80].

Streptomyces was the most dominant genus among the isolates, which agrees with the findings of Zhang et al. [81]. Genus Nocardiposis, with its two species Nocardiposis alba and Nocardiposis dassonvillei, has been suggested [82] as the second most common genus after Streptomyces and that too agrees with our findings. Further, the reporting of the most prevalent genera, including Agrococcus, Arthrobacter, Brevibacterium, Kocuria, Microbacterium and Micrococcus, from sponges in our study is consistent with previous reports from other study areas, including the South China Sea [17], the Yellow Sea [81], the Mediterranean Sea [26], the coast of Florida in the USA [21] and the northern coast of Brazil [83], indicating that there are common trends in the discovery of actinobacteria from sponges.

Among the first reports from the marine environment from our study, Aeromicrobium massiliense and Glutamicibacter mysorens are known from human faecal microbiota [84] and sewage [85], respectively. The presence of these two species in the sediments along the collection site Harne $\left(17.81^{\circ} \mathrm{N}\right.$, $73.09^{\circ} \mathrm{E}$ ) may suggest faecal pollution in this area. Runoff from nearby urban, rural and agricultural lands could also explain the presence of other known terrestrial actinobacterial species from marine environments. 

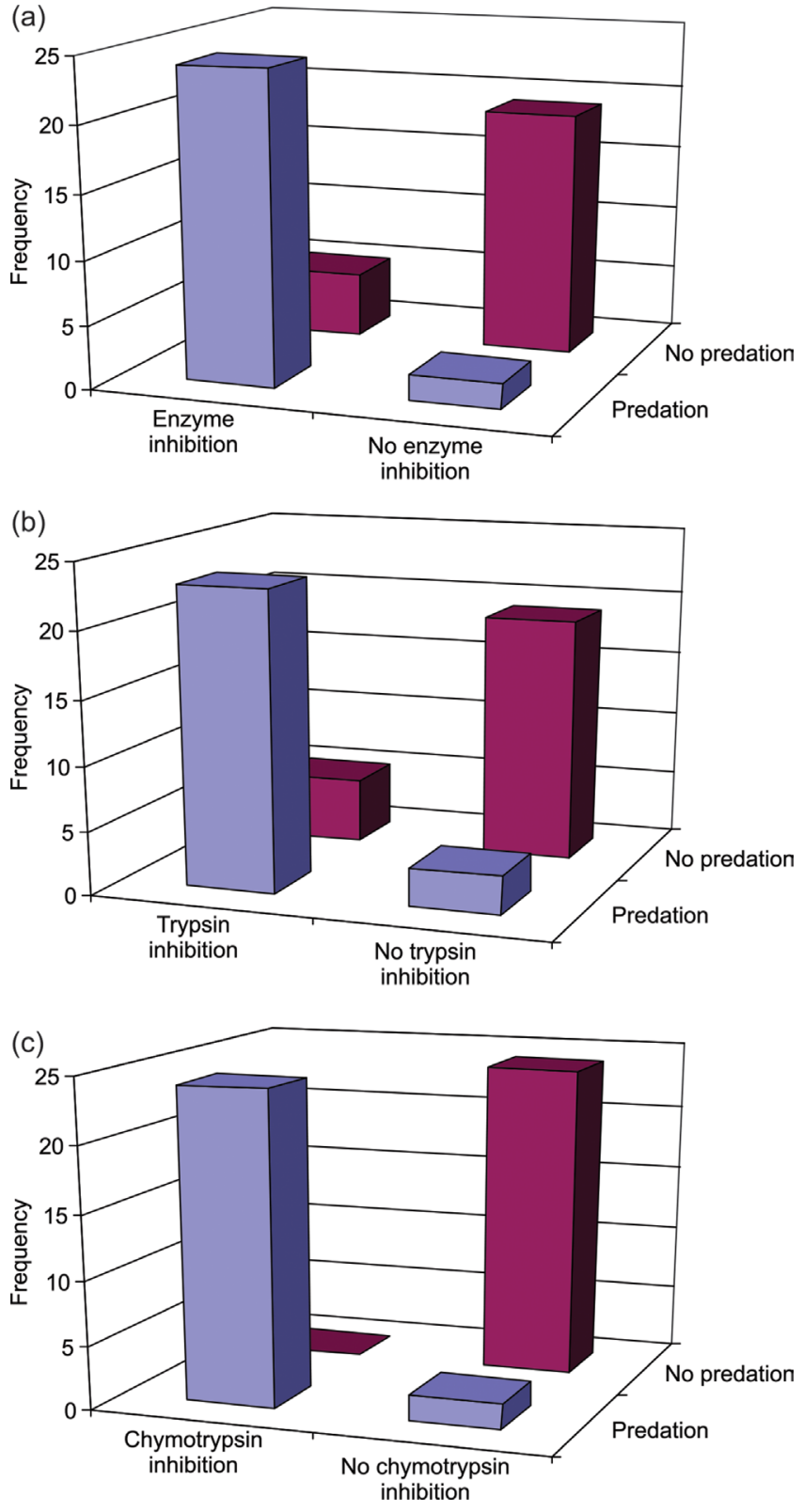

Fig. 5. Association between enzyme inhibition and predation in actinobacterial isolates. Predation was significantly associated with (a) inhibition of any one of the four enzymes tested $\left(\chi^{2}=26.172, P<0.0001\right)$, (b) inhibition of trypsin $\left(\chi^{2}=23.165, P<0.0001\right)$ and (c) inhibition of chymotrypsin $\left(\chi^{2}=42.604, P<0.0001\right)$.

Although predation is a widespread behaviour in the bacterial kingdom, $\delta$-proteobacteria of the orders Myxococcales and Bdellovibrionales have received more attention [86] than other taxa, especially Gram-positive bacteria such as actinobacteria. Among the phylum Actinobacteria, only three genera, namely Agromyces, Streptomyces and Streptoverticillium, are known to have epibiotic predatory behaviour against other bacterial species [39-42, 87-89]. In the current study, for the first time, we show predation in six other genera of the phylum Actinobacteria, namely Brevibacterium, Glutamicibacter,
Micromonospora, Nocardiopsis, Rhodococcus and Rothia. Kumbhar et al. [41] argued that predatory behaviour is widespread in the genus Streptomyces and even in the current study we observed that all the isolates of Streptomyces used for screening showed predation on Gram-positive as well as Gram-negative prey.

Since sponges are sessile and lack other anti-predator defences, it has been suggested that secondary metabolites of bacteria can provide sponges with chemical defence $[34,38]$. However, we did not observe any significant association between the source of actinobacterial isolation and antibiotic production, suggesting that isolates even from environment were equally likely to produce antimicrobials as isolates recovered from sponges. Our finding therefore supports the recent suggestions that antibiotics may have other roles, including as intermicrobial signalling agents, instead of just being weapons $[34,90]$. Nevertheless, there was a significant association between the source of isolation and predatory activity, with proportionately more predators among the isolates recovered from sponge. Ecologically this makes sense. As the sponges are filter feeders and have regular intake of environmental bacteria, sponge-associated actinobacteria will have better predation opportunities. It is also possible that the predatory activity of sponge-associated actinobacteria could have evolved as a mutualistic activity, as it can defend sponges from pathogenic bacterial invasions.

Actinobacteria are known to produce several enzyme inhibitors $[29,30,91]$. However, for the first time we show a strong association between predation and enzyme inhibition, specifically inhibition of trypsin and chymotrypsin, where predators produced proportionally more enzyme inhibitors than non-predators. Predators themselves are known to produce a variety of hydrolytic enzymes for degrading prey [92]. Therefore, it is possible that the production of enzyme inhibitors safeguards their own cells from being a target of the enzyme. It is also possible that enzyme inhibitors also protect actinobacteria from hydrolytic enzymes produced from the sponge host and other microbiota.

An interesting observation that we made, when comparing predation and antibiotic production by actinobacteria, was that, while predation was equally effective against Gram-positive and Gram-negative target species, antibiotic production was mainly effective against Gram-positive bacteria. Recently, Ibrahimi et al. [89] suggested that there are some bio-active secondary metabolites that co-cultured actinobacteria produce in the presence of prey cells. It is therefore possible that studying the predatory behaviour of actinobacteria and predation-specific metabolites could lead to the discovery of novel therapeutic agents that are more broad spectrum.

Although actinobacteria are known to be rich in secondary metabolites, extracellular enzymes and enzyme inhibitors, the ecological role of these extracellular bioactive molecules is little known. We suggest that studying the ecological correlates of bioactivity and the inter-correlation patterns of different types of bioactivity can be a useful tool in understanding the ecological origins of bioactivity and testing alternative ecological hypotheses. 


\section{CONCLUSION}

Sponges and their associated environments in intertidal zones along the northern parts of the western coast of India are rich in actinobacterial diversity, with 19 families and 28 genera, which could be attributed to 95 putative species using MPTP and 100 putative species based on bPTP methods. Although at the genus level the trends in the discovery of actinobacteria isolated from sponges were consistent with previous studies from different study areas, we provide the first report of nine species, namely Brachybacterium murisi, Jonesia denitrificans, Nocardiopsis salina, Pseudonocardia kongjuensis, Rhodococcus zopfi, Rothia terrae, Serinicoccus marinus, Streptomyces smyrnaeus and Streptomyces viridobrunneus. Non-obligate epibiotic predatory behaviour was widespread among actinobacterial genera and we provide the first report of predatory activity in Brevibacterium, Glutamicibacter, Micromonospora, Nocardiopsis, Rhodococcus and Rothia. Sponge-associated actinobacteria showed significantly more predatory behaviour than environmental isolates, and we hypothesize that predatory actinobacteria might provide sponges with defence against pathogenic bacteria. While antibiotics produced from actinobacterial isolates affected Gram-positive target bacteria, with little to no effect on Gram-negative bacteria, predation targeted both Gram-positive and Gram-negative prey with equal propensity, suggesting that study of predation specific metabolites might provide novel therapeutic agents with broad-spectrum activity. Actinobacterial isolates from both sponge and associated environments produced inhibitors of serine proteases and angiotensin-converting enzyme. Predatory behaviour was strongly associated with inhibition of trypsin and chymotrypsin, which might be helpful for the actinobacteria in overcoming the effects of proteolytic enzymes produced by sponge host and other microbiota. Understanding the diversity and associations among various actinobacterial activities - with each other and the source of isolation - can provide new insights into marine microbial ecology and provide opportunities to isolate novel therapeutic agents.

\section{DATA AVAILABILITY}

The sequences of the 16S rRNA gene of the studied isolates were submitted to the National Center for Biotechnology Information's (NCBI's) GenBank under the accession numbers MN339687-MN339897 and MT598037MT598065. Actinobacterial cultures were deposited in the Microbial Culture Collection (MCC) of the National Centre for Microbial Resource, National Centre for Cell Sciences, Pune, India (accession numbers are provided in the Table S1). All the data used for analysis are provided in Tables S1 and S2.

Funding information

This work was funded by the Maharashtra Gene Bank Programme (RGSTC/File-2007/DPP-054/CR-28) of the Rajiv Gandhi Science and Technology Commission, Government of Maharashtra, India.
Acknowledgements

We thank the Director and Chair of Biology, Indian Institute of Science Education and Research (IISER), Pune, and Principal, M.E.S. Abasaheb Garware College, Pune for providing infrastructural facilities. We are thankful to V.S. Rao, IISER Pune, for support an encouragement.

\section{Author contributions}

M.W., U.B. and N.D., conceived and designed the study. U.B., N.S., K.H., A.P., U.L., T.G., K.P., A.J., R.S., H.V and V.T., performed the study. N.D. and M.W., analysed the data. N.D., U.B. and M.W., wrote the manuscript with input from other authors. All authors contributed to the proofreading of the manuscript.

Conflicts of interest

The authors declare that there are no conflicts of interest.

\section{References}

1. Ward AC, Bora N. Diversity and biogeography of marine actinobacteria. Curr Opin Microbiol 2006;9:279-286.

2. Taylor MW, Radax R, Steger D, Wagner M. Sponge-associated microorganisms: evolution, ecology, and biotechnological potential. Microbiol Mol Biol Rev 2007;71:295-347.

3. Lam KS. Discovery of novel metabolites from marine actinomycetes. Curr Opin Microbiol 2006:9:245-251.

4. Barka EA, Vatsa P, Sanchez L, Gaveau-Vaillant N, Jacquard C, et al. Taxonomy, physiology, and natural products of Actinobacteria. Microbiol Mol Biol Rev 2016;80:1-43.

5. Tan LTH, Ser HL, Yin WF, Chan KG, Lee LH, et al. Investigation of antioxidative and anticancer potentials of Streptomyces sp. MUM256 isolated from Malaysia mangrove soil. Front Microbiol 2015;6:1316.

6. Braesel J, Lee JH, Arnould B, Murphy BT, Eustáquio AS. Diazaquinomycin biosynthetic gene clusters from marine and freshwater actinomycetes. J Nat Prod 2019:82:937-946.

7. Mincer TJ, Jensen PR, Kauffman CA, Fenical W. Widespread and persistent populations of a major new marine actinomycete taxon in ocean sediments. Appl Environ Microbiol 2002;68:5005-5011.

8. Kokare CR, Mahadik KR, Kadam SS. Isolation of bioactive marine actinomycetes from sediments isolated from Goa and Maharashtra coastlines (west coast of India). Indian J Mar Sci 2004;33:248-256.

9. Jose PA, Jebakumar SRD. Unexplored hypersaline habitats are sources of novel actinomycetes. Front Microbiol 2014;5:242.

10. Pathom-Aree W, Stach JE, Ward AC, Horikoshi K, Bull AT, et al. Diversity of actinomycetes isolated from Challenger Deep sediment $(10,898 \mathrm{~m})$ from the Mariana Trench. Extremophiles 2006:10:181-189.

11. Mohammadipanah F, Wink J. Actinobacteria from arid and desert habitats: diversity and biological activity. Front Microbiol 2016:6:1541

12. Shivlata L, Tulasi S. Thermophilic and alkaliphilic Actinobacteria: biology and potential applications. Front Microbiol 2015;6:1014.

13. Riquelme C, Hathaway JJM, Enes Dapkevicius MLN, Miller AZ, Kooser A, et al. Actinobacterial diversity in volcanic caves and associated geomicrobiological interactions. Front Microbiol 2015;6:1342.

14. Yang J, Li X, Huang $L$, Jiang $H$. Actinobacterial diversity in the sediments of five cold springs on the Qinghai-Tibet plateau. Front Microbiol 2015;6:1345.

15. BookAJ,Lewin GR, McDonald BR, Takasuka TE, Wendt-PienkowskiE, et al. Evolution of high cellulolytic activity in symbiotic Streptomyces through selection of expanded gene content and coordinated gene expression. PLoS Biol 2016;14:e1002475

16. Qin Z, Munnoch JT, Devine R, Holmes NA, Seipke RF, et al. Formicamycins, antibacterial polyketides produced by Streptomyces formicae isolated from African Tetraponera plant-ants. Chem Sci 2017:8:3218-3227.

17. Li Z, Sun W, Zhang F, He L, Loganathan K. Actinomycetes from the South China Sea sponges: isolation, diversity and potential for aromatic polyketides discovery. Front Microbiol 2015;6:1048. 
18. Mahmoud HM, Kalendar AA. Coral-associated Actinobacteria: diversity, abundance, and biotechnological potentials. Front Microbiol 2016;7:204.

19. Trujillo ME, Riesco R, Benito P, Carro L. Endophytic actinobacteria and the interaction of Micromonospora and nitrogen fixing plants. Front Microbiol 2015;6:1341.

20. Goodfellow M. Actinobacteria phyl. nov. Whitman W (eds). In: Bergey's Manual of Systematics of Archaea and Bacteria. New York: Wiley; 2015. https://dx.doi.org/10.1002/9781118960608. pbm00002

21. Montalvo NF, Mohamed NM, Enticknap JJ, Hill RT. Novel actinobacteria from marine sponges. Antonie Van Leeuwenhoek 2005:87:29-36.

22. Manivasagan P, Venkatesan J, Sivakumar K, Kim SK. Actinobacterial enzyme inhibitors-A review. Crit Rev Microbiol 2015;41:261-272.

23. Olano C, Méndez C, Salas J. Antitumor compounds from marine actinomycetes. Mar Drugs 2009;7:210-248.

24. Trischman JA, Tapiolas DM, Jensen PR, Dwight R, Fenical W, et al. Salinamides A and B: anti-inflammatory depsipeptides from a marine streptomycete. J American Chem Soc 1994;116:757-758.

25. Pimentel-Elardo SM, Kozytska S, Bugni TS, Ireland CM, Moll H, et al. Anti-parasitic compounds from Streptomyces sp. strains isolated from Mediterranean sponges. Mar Drugs 2010;8:373-380.

26. Cheng C, Maclntyre L, Abdelmohsen UR, Horn H, Polymenakou PN, et al. Biodiversity, anti-trypanosomal activity screening, and metabolomic profiling of actinomycetes isolated from Mediterranean sponges. PLOS ONE 2015;10:e0138528.

27. Gandhimathi R, Arunkumar M, Selvin J, Thangavelu T, Sivaramakrishnan $\mathrm{S}$, et al. Antimicrobial potential of sponge associated marine actinomycetes. J Mycol Med 2008;18:16-22.

28. Abdelfattah MS, Elmallah MIY, Hawas UW, Abou El-Kassema LT, Eid MAG. Isolation and characterization of marine-derived actinomycetes with cytotoxic activity from the Red Sea coast. Asian Pacific Journal of Tropical Biomedicine 2016;6:651-657.

29. Manivasagan $\mathrm{P}$, Kang KH, Sivakumar K, Li-Chan EC, Oh HM, et al. Marine actinobacteria: an important source of bioactive natural products. Environ Toxicol Pharmacol 2014:38:172-188.

30. Imada C. Enzyme inhibitors and other bioactive compounds from marine actinomycetes. Antonie Van Leeuwenhoek 2005;87:59-63.

31. Watve MG, Tickoo R, Jog MM, Bhole BD. How many antibiotics are produced by the genus Streptomyces? Arch Microbiol 2001;176:386-390.

32. Mahapatra GP, Raman S, Nayak S, Gouda S, Das G, et al. Metagenomics approaches in discovery and development of new bioactive compounds from marine actinomycetes. Curr Microbiol 2020;77:645-656.

33. Subramani R, Sipkema D. Marine rare actinomycetes: A promising source of structurally diverse and unique novel natural products. Marine Drugs 2019:17:249.

34. Kumbhar C, Watve M. Why antibiotics: A comparative evaluation of different hypotheses for the natural role of antibiotics and an evolutionary synthesis. Nat Sci 2013;5:26-40.

35. Vetter YA, Deming JW, Jumars PA, Krieger-Brockett BB. A predictive model of bacterial foraging by means of freely released extracellular enzymes. Microbial Ecology 1998;36:75-92.

36. Lee 00, Wong YH, Qian PY. Inter- and intraspecific variations of bacterial communities associated with marine sponges from San Juan Island, Washington. Appl Environ Microbiol 2009;75:3513-3521.

37. Thomas TR, Kavlekar DP, LokaBharathi PA. Marine drugs from sponge-microbe association - a review. Mar Drugs 2010;8:1417-1468.

38. Lee YK, Lee JH, Lee HK. Microbial symbiosis in marine sponges. $J$ Microbiol 2001;39:254-264.

39. Casida LE. Bacterial predators of Micrococcus luteus in soil. Appl Environ Microbiol 1980;39:1035-1041.

40. Casida LE. Interaction of Agromyces ramosus with other bacteria in soil. Appl Environ Microbiol 1983;46:881-888.
41. Kumbhar C, Mudliar P, Bhatia L, Kshirsagar A, Watve M. Widespread predatory abilities in the genus Streptomyces. Arch Microbiol 2014;196:235-248.

42. Pund A, Holkar K, Watve M, Baig UI. Bacterial predator prey and the third beneficiary. Matters (Zur) 2020.

43. Harir M, Bendif H, Bellahcene M, Fortas Z, Pogni R. Streptomyces secondary metabolites. Enany S (eds). In: Basic Biology and Applications of Actinobacteria. London: IntechOpen; 2018. pp. 99-122.

44. Van der Meij A, Worsley SF, Hutchings MI, van Wezel GP. Chemical ecology of antibiotic production by actinomycetes. FEMS Microbiol Rev 2017:41:392-416.

45. Singh HS. Marine protected areas in India. Indian J Marine Sci 2003;32:226-233.

46. De K, Venkataraman K, Ingole B. Current status and scope of coral reef research in India: A bio-ecological perspective. Indian J Geo Marine Sci 2017;46:647-662.

47. Kathiresan K. Mangrove forests of India. Curr Sci 2018;114:976-981.

48. Mote S, Gupta V, De K, Nanajkar M, Damare SR, et al. Bacterial diversity associated with a newly described bioeroding sponge, Cliona thomasi, from the coral reefs on the West Coast of India. Folia Microbiol 2020.

49. Watve M, Shejval V, Sonawane C, Rahalkar M, Matapurkar A, et al. The "K" selected oligophilic bacteria: A key to uncultured diversity. Curr Sci 2000;78:1535-1542.

50. ZoBell CE. Studies on marine bacteria. I. The cultural requirements of heterotrophic aerobes. J Mar Res 1941;4:41-75.

51. Takizawa M, Colwell RR, Hill RT. Isolation and diversity of actinomycetes in the Chesapeake Bay. Appl Environ Microbiol 1993;59:997-1002.

52. Jiang $\mathrm{X}$, Ellabaan $\mathrm{MMH}$, Charusanti $\mathrm{P}$, Munck $\mathrm{C}$, Blin $\mathrm{K}$, et al. Dissemination of antibiotic resistance genes from antibiotic producers to pathogens. Nature Comm 2017:8:15784.

53. Heuer H, Krsek M, Baker P, Smalla K, Wellington EM. Analysis of actinomycete communities by specific amplification of genes encoding $16 \mathrm{~S}$ rRNA and gel-electrophoretic separation in denaturing gradients. Appl Environ Microbiol 1997;63:3233-3241.

54. Hall TA. BioEdit: a user-friendly biological sequence alignment editor and analysis program for Windows 95/98/NT. Nucleic Acids Symp Ser 1999:41:95-98.

55. Altschul SF, Gish W, Miller W, Myers EW, Lipman DJ. Basic local alignment search tool. J Mol Biol 1990;215:403-410.

56. Edgar RC. MUSCLE: multiple sequence alignment with high accuracy and high throughput. Nucleic Acids Res 2004;32:1792-1797.

57. Kumar S, Stecher G, Tamura K. MEGA7: molecular evolutionary genetics analysis version 7.0 for bigger datasets. Mol Biol Evol 2016;33:1870-1874.

58. Kalyaanamoorthy S, Minh BQ, Wong TKF, von Haeseler A, Jermiin LS ModelFinder: Fast model selection for accurate phylogenetic estimates. Nat Methods 2017;14:587-589.

59. Schwarz G. Estimating the dimension of a model. Ann Stat 1978;6:461-464.

60. Nei M, Kumar S. Molecular Evolution and Phylogenetics. UK: Oxford University Press; 2000.

61. Nguyen LT, Schmidt HA, von Haeseler A, Minh BQ. IQ-TREE: a fast and effective stochastic algorithm for estimating maximum likelihood phylogenies. Mol Biol Evol 2015;32:268-274.

62. Hoang DT, Chernomor 0 , von Haeseler A, Minh BQ, Vinh LS UFBoot2: Improving the ultrafast bootstrap approximation. Mol Biol Evol 2018;35:518-522.

63. Rambaut A. FigTree. ver 1.4.3. 2009. http://tree.bio.ed.ac.uk/software/\%ef\%ac\%81gtree/

64. Zhang J, Kapli P, Pavlidis P, Stamatakis A. A general species delimitation method with applications to phylogenetic placements. Bioinformatics 2013;29:2869-2876. 
65. Valli S, Suvathi SS, Aysha OS, Nirmala P, Vinoth KP, et al. Antimicrobial potential of Actinomycetes species isolated from marine environment. Asian Pac J Trop Biomed 2012;2:469-473.

66. Velho-Pereira S, Kamat NM. Antimicrobial screening of actinobacteria using a modified cross-streak method. Indian J Pharm Sci 2011;73:223-228

67. Cheung AL, Ying P, Fischetti VA. A method to detect proteinase activity using unprocessed X-ray films. Anal Biochem 1991:193:20-23.

68. Tripathi VR, Kumar S, Garg SK. A study on trypsin, Aspergillus flavus and Bacillus sp. protease inhibitory activity in Cassia tora (L.) syn Senna tora (L.) Roxb. seed extract. BMC Complement Altern Med 2011;11:56

69. Cushman DW, Cheung HS. Spectrophotometric assay and properties of the angiotensin-converting enzyme of rabbit lung. Biochem Pharmacol 1971;20:1637-1648.

70. Ng KH, Lye HS, Easa AM, Liong MT. Growth characteristics and bioactivity of probiotics in tofu-based medium during storage. Ann Microbiol 2008:58:477-487.

71. Hammer $\emptyset$, Harper DAT, Ryan PD. Past: Paleontological statistics software package for education and data analysis. Palaeontologia Electronica 2001;4:1-9.

72. Padgitt PJ, Moshier SE. Mycobacterium poriferae sp. nov., a scotochromogenic, rapidly growing species isolated from a marine sponge. Int J Syst Evol Microbiol 1987;37:186-191.

73. Elfalah HW, Usup G. Ahmad A. Anti-microbial properties of secondary metabolites of marine Gordonia tearrae extract. J Agric Sci 2013;5:94-101

74. Santos JD, Vitorino I, De la Cruz M, Díaz C, Cautain B, et al. Bioactivities and extract dereplication of Actinomycetales isolated from marine sponges. Front Microbiol 2019;10:727.

75. Kiran GS, Sabarathnam B, Selvin J. Biofilm disruption potential of a glycolipid biosurfactant from marine Brevibacterium casei. FEMS Immunol Med Microbiol 2010;59:432-438.

76. Palomo S, González I, de la Cruz M, Martín J, Tormo JR, et al. Sponge-derived Kocuria and Micrococcus spp. as sources of the new thiazolyl peptide antibiotic kocurin. Mar Drugs 2013;11:1071-1086.

77. Stach JEM, Maldonado LA, Masson DG, Ward AC, Goodfellow M, et al. Statistical approaches for estimating actinobacterial diversity in marine sediments. Appl Environ Microbiol 2003;69:6189-6200.

78. Satheeja SV, Jebakumar SR. Phylogenetic analysis and antimicrobial activities of Streptomyces isolates from mangrove sediment. J Basic Microbiol 2011:51:71-79.
79. Yi H, Schumann P, Sohn K, Chun J. Serinicoccus marinus gen. nov. sp. nov., a novel actinomycete with L-ornithine and L-serine in the peptidoglycan. Int J Syst Evol Microbiol 2004;54:1585-1589.

80. Shinde VL, Meena RM, Shenoy BD. Phylogenetic characterization of culturable bacteria and fungi associated with tarballs from Betul beach, Goa, India. Mar Pollut Bull 2018;128:593-600.

81. Zhang $\mathrm{H}$, Zhang $\mathrm{W}$, Jin $\mathrm{Y}$, Jin $\mathrm{M}, \mathrm{Yu} \mathrm{X}$. A comparative study on the phylogenetic diversity of culturable actinobacteria isolated from five marine sponge species. Antonie van leeuwenhoek 2008:93:241-248

82. Bennur T, Kumar AR, Zinjarde S, Javdekar V. Nocardiopsis species: Incidence, ecological roles and adaptations. Microbiol Res 2015:174:33-47.

83. Menezes CB, Bonugli-Santos RC, Miqueletto PB, Passarini MR Silva $\mathrm{CH}$, et al. Microbial diversity associated with algae, ascidians and sponges from the north coast of São Paulo state. Microbiol Res 2010;165:466-482

84. Ramasamy D, Kokcha S, Lagier J-C, Nguyen T-T, Raoult D, et al Genome sequence and description of Aeromicrobium massiliense sp. nov. Stand Genomic Sci 2012;7:246-257.

85. Nand K, Rao DV. Arthrobacter mysorens-a new species excreting L-glutamic acid. Zentralbl Bakteriol Parasitenkd Infektionskr Hyg 1972;127:324-331.

86. Jurkevitch E. Predatory behaviors in bacteria-diversity and transitions. Microbe 2007:2:67-73.

87. Casida LE. Minireview: Nonobligate bacterial predation of bacteria in soil. Microb Ecol 1988;15:1-8.

88. Zeph LR, Casida LE. Gram-negative versus gram-positive (actinomycete) nonobligate bacterial predators of bacteria in soil. Appl Environ Microbiol 1986:52:819-823.

89. Ibrahimi M, Korichi W, Hafidi M, Lemee L, Ouhdouch Y, et al. Marine Actinobacteria: screening for predation leads to the discovery of potential new drugs against multidrug-resistant bacteria. Antibiotics 2020:9:91.

90. Linares JF, Gustafsson I, Baquero F, Martinez JL. Antibiotics as intermicrobial signaling agents instead of weapons. Proc Natl Acad Sci U S A 2006;103:19484-19489.

91. Shintre NA, Tamhane VA, Baig U, Pund A, Patwardhan R, et al Diversity of culturable actinobacteria producing protease inhibitors from the intertidal zones of Maharashtra, India. Curr Microbiol 2020;77:3555-3564.

92. Pérez J, Moraleda-Muñoz A, Marcos-Torres FJ, Muñoz-Dorado J. Bacterial predation: 75years and counting! Environ Microbiol 2016;18:766-779.

\section{Five reasons to publish your next article with a Microbiology Society journal}

1. The Microbiology Society is a not-for-profit organization.

2. We offer fast and rigorous peer review - average time to first decision is 4-6 weeks.

3. Our journals have a global readership with subscriptions held in research institutions around the world.

4. $80 \%$ of our authors rate our submission process as 'excellent' or 'very good'.

5. Your article will be published on an interactive journal platform with advanced metrics.

Find out more and submit your article at microbiologyresearch.org. 